\title{
GALERKIN'S INDIRECT VARIATIONAL METHOD IN ELASTIC STABILITY ANALYSIS OF ALL EDGES CLAMPED THIN RECTANGULAR FLAT PLATES
}

\author{
J. C. Ezeh ${ }^{1}$, Ibearugbulem, M. Owus ${ }^{2}$ H. E. Opara ${ }^{3}$, and, O. A. Oguaghamba ${ }^{4}$ \\ ${ }^{I}$ Department of Civil Engineering, Federal University of Technology, Owerri \\ ${ }^{2}$ Department of Civil Engineering, Federal University of Technology, Owerri \\ ${ }^{3}$ Department of Civil Engineering, Imo State University, Owerri \\ ${ }^{4}$ Department of Civil Engineering, Imo State University, Owerri
}

\begin{abstract}
The work is to use the energy approach in the form of indirect variational principle (Galerkin's method) for buckling analysis elastic of thin rectangular plates with all edges clamped. The Galerkin method has been used to solve problems in structural engineering such as structural mechanics, dynamics, fluid flow, heat and mass transfer, acoustics, neutron transport and others. The Galerkin method can be used to approximate the solution to ordinary differential equations, partial differential equations and integral equations with a polynomial involving a set of parameters called characteristic orthogonal polynomials. The buckling loads from this study were compared with those of previous researches. The results showed that the average percentage differences recorded for CCCC plates are 0.735 to 4.702. These differences showed that the shape functions formulated by COP has rapid convergence and is very good approximation of the exact displacement functions of the deformed thin rectangular plate under in-plane loading when applied to Galerkin's buckling load for isotropic plates. An indirect variation principle (based on Galerkin's method) could be used in confidence to satisfactorily analyze real time rectangular thin plates of various boundary conditions under in-plane loadings. The results obtained herein are very close to the results obtained by previous research works that used different methods of analysis.
\end{abstract}

Keywords: Indirect Variational Method; Galerkin Method; Buckling loads; Characteristic Orthogonal Polynomials; Approximate solution; Non linear functional; Convergence; Boundary conditions

\section{INTRODUCTION}

Structural stability is an important issue in the design of many types of civil, mechanical and aeronautical structures. This is especially true for structures having one or two dimensions that are small in relations to the rest, such as beam-columns, plates and shells. These structures are susceptible to lateral instability commonly idealized as an elastic buckling.

Buckling of the plates could be studied, in general perspective, using the equilibrium, energy and numeric approaches (Reddy, 2002). Equilibrium approach is also regarded as Euler approach. It sums all the forces acting on a continuum to zero. The approach tends to find solution of the governing differential equation by direct integration and satisfying the boundary conditions of the four edges of the plate.

Numerical approach is a good alternative to the Euler approach. Some examples of this approach include truncated double Fourier series, finite difference, finite strip, RungeKutta and finite element methods among others. The problem with these numerical solutions is that the accuracy of the solution is dependent on the amount of work to be done. For instance, if one is using finite element method, the more the number of elements used in the analysis the closer the approximate solution to the exact solution. Hence, when a plate has to be divided into several elemental plates for an accurate solution to be reached, then the extensive analysis is involved, requiring enormous time to be invested.

Energy approach, on the other hand, sums all the work (strain energy and potential energy or external work) on the continuum to be equal to total potential energy (Iyengar, 1988). This approach is quite different from Euler and numerical approaches. The solution from it agrees approximately with the exact solution. Typical examples of energy approaches are Ritz, Raleigh-Ritz; Galerkin, minimum potential energy etc. These methods are called variational methods. They seek to minimize the total potential energy functional in order to get the stability matrix.

In all these methods, the accuracy of the solution is dependent on the accuracy of the approximate deflection function (shape 
function). The more the approximate shape function gets closer to the exact solution.

Many scholars have used different approaches to obtain shape functions for solving plates' buckling problem.

lyengar (1988) used the variation of total potential energy method, and assumed a double trigonometric shape function of the form:

$$
W=A\left(1-\operatorname{Cos} \frac{2 x}{a}\right)\left(1-\operatorname{Cos} \frac{2 y}{b}\right)
$$

He obtained the buckled plate critical load in first mode to be

$$
N_{X}=\left(\frac{4}{\mathrm{P}^{2}}+2.667+4 \mathrm{P}^{2}\right) \frac{D \pi^{2}}{b^{2}}
$$

Ibearugbulem \& Ezeh (2013) used shape function derived from Taylor-Macluarin series and applied it to direct energy variational method according Rayleigh - Ritz. They obtained for thin rectangular plate with all edges clamped as:

$$
W(x, y)=K\left(R^{2}-2 R^{3}+R^{4}\right)\left(Q^{2}-2 Q^{3}+Q^{4}\right)
$$

They obtained the first mode critical buckling load as:

$$
N_{x}=\left(\frac{4.255}{P^{2}}+2.428+4.255 P^{2}\right) \frac{D \pi^{2}}{b^{2}}
$$

(Fok, 1980) used finite difference method in equilibrium (Euler) approach and obtained the coefficient of $\mathrm{K}$ as 10.12 .

Where, $\mathrm{K}$ is coefficient of $\frac{D \pi^{2}}{b^{2}}$.

(Levy \& Greenman, 1942) used an infinite series for the shape function in equilibrium (Euler) approach and obtained the coefficient of $\mathrm{K}$ value as 10.07 .

\section{CHARACTERISTIC ORTHOGONAL POLYNOMIALS}

A class of characteristic orthogonal polynomial (COPs) can be constructed using Gram-Schmidt process and then these polynomials are employed as deflection functions in stability problems (Chakraverty, 2009). Different series types, viz., trigonometric, hyperbolic, polynomial, give different results for the same number of terms in the series and the efficiency of the solution will depend to some extent on the type of series chosen (Brown \& Stone, 1997). (Bhat, 1985a) used the GramSchmidt orthogonalization procedure to generate the COPs for one dimension and showed that the orthogonal polynomials offered improved convergence and better results.
To use COPs in the Galerkin method for the study of non linear elastic problems, first the orthogonal polynomials are generated over the domain of the structural member, satisfying the appropriate boundary conditions. After the first member function is constructed as the simplest polynomial that satisfies the boundary conditions, the higher members are constructed using the well-known Gram-Schmidt procedure (Wendroff, 1961); (Szego, 1967); (Freud, 1971); (Chihara, 1978).

\subsection{Characteristic Orthogonal Polynomials in One}

\section{Dimension}

Here, the first member of the orthogonal polynomial set $\varphi(k)$, which is function of a single variable say $\mathrm{x}$, is chosen as the simplest polynomial of the least order that satisfies both the geometrical and the natural boundary conditions. In general, the first member is written in the form:

$$
\begin{gathered}
\varphi(k)=c_{o}+c_{1} k+c_{2} k^{2}+c_{3} k^{3}+\cdots+c_{\infty-1} k^{\infty-1} \\
+c_{\infty} k^{\infty}
\end{gathered}
$$

The compact form of Equation 5.0 is given as:

$$
\varphi(k)=\sum_{t=0}^{\infty} c_{t} k^{t}
$$

Where, the constants $c_{t}$ can be found by applying the boundary condition of the problem. It is to be mentioned here that this function should satisfy at least the geometrical boundary condition. But, if the function also satisfies the natural boundary condition, then the resulting solution will be far better (Bhat, 1985a).

\subsection{Characteristic Orthogonal Polynomials in Two}

\section{Dimensions}

The displacement function for rectangular plate, which a two dimensional structure in $\mathrm{x}$ and $\mathrm{y}$ axes is assumed as a product of two independent functions; one of which is a pure function of $\mathrm{x}$ and the other is of $\mathrm{y}$ so that:

$$
W(x, y)=F(x) \cdot G(y)=\sum_{m=0}^{\infty} \sum_{\mathrm{n}=0}^{\infty} X_{m} x^{m} Y_{n} y^{n}
$$

Expressing Equation in the form of non-dimensional parameters, say R and $\mathrm{Q}$ for $\mathrm{x}$ and $\mathrm{y}$ directions respectively:

Then,

$$
\mathrm{x}=\mathrm{aR} ; \mathrm{y}=\mathrm{bQ} \quad 8.0
$$

$$
\mathrm{w}(\mathrm{R}, \mathrm{Q})=\sum_{\mathrm{m}=0}^{\infty} \sum_{n=0}^{\infty} A_{m} \mathrm{~B}_{\mathrm{n}} \mathrm{R}^{m} \mathrm{Q}^{\mathrm{n}}
$$




$$
A_{m}=X_{m} \mathrm{a}^{\mathrm{m}} \quad B_{n}=Y_{n} \mathrm{~b}^{\mathrm{n}} \quad 10.0
$$

Since the buckling equation of plate, is a fourth order differential and the density of the plate is constant, then, the value of $\mathrm{m}$ and $\mathrm{n}$ in Equation 9.0 must be equal to 4 . If the variation of loading is linear or a second degree parabola, the value of the power $m$ and $n$ will then be 5 or 6 respectively and so on (Onyeyili, 2012).

Expanding Equation 9.0:

$$
\begin{gathered}
w(R, Q)=\left(A_{0}+A_{1} R+A_{2} R^{2}+A_{3} R^{3}+A_{4} R^{4}\right)\left(B_{0}+B_{1} Q\right. \\
\left.+B_{2} Q^{2}+B_{3} Q^{3}+B_{4} Q^{4}\right)
\end{gathered}
$$

The coefficients $A_{m}$ and $B_{n}$ of the series are determined from the boundary conditions at the edges of the plate.

\section{Boundary conditions}

- Deflections at all edges are zero and Slope at all edges are zero

$$
\begin{gathered}
W_{R}(R=0)=0, A_{0}=0 \\
W_{Q}(Q=0)=0, B_{0}=0 \\
W_{R}^{I}(R=0)=0, A_{1}=0 \\
W_{Q}^{I}(Q=1)=0, B_{1}=0 \quad 13.0 \\
\begin{array}{c}
W_{R}(R=1)=0, A_{2}=-\left(A_{3}+A_{4}\right), \\
W_{Q}(Q=1)=0, B_{2}=-\left(B_{3}+B_{4}\right)
\end{array} \\
W_{R}^{I}(R=0)=0, A_{3}=-2 A_{4}, \\
W^{I}{ }_{Q}(Q=1)=0, B_{3}=-2 B_{4}
\end{gathered}
$$

Then, solving Equation 14.0 and 15.0 by substitution method separately relative to their directions

$$
W(R, Q)=A\left(R^{2}-2 R^{3}+R^{4}\right)\left(Q^{2}-2 Q^{3}+Q^{4}\right)
$$

Where $\mathrm{A}=\boldsymbol{A}_{\mathbf{4}} \boldsymbol{\beta}_{\mathbf{4}}$

\section{APPLICATION OF GALERKIN METHOD}

Governing partial differential equation for plate was given by (Kirchoff, 1885) and (Saint-Venant, 1883) as:

$$
\begin{aligned}
& P+N_{x} \frac{\partial^{2} w}{\partial x^{2}}+2 N_{x y} \frac{\partial^{2} w}{\partial x \partial y}+N_{y} \frac{\partial^{2} w}{\partial y^{2}} \\
&-\mathrm{D}\left(\frac{\partial^{4} \mathrm{w}}{\partial \mathrm{x}^{4}}+2 \frac{\partial^{4} \mathrm{w}}{\partial \mathrm{x}^{2} \partial \mathrm{y}^{2}}+\frac{\partial^{4} \mathrm{w}}{\partial \mathrm{y}^{4}}\right)=0 \quad 17.0
\end{aligned}
$$

For plate that is only under in-plane loads, $\mathrm{P}$ will be dropped from Eq. (2.4) and the general equation becomes

$$
\begin{aligned}
& N_{x} \frac{\partial^{2} w}{\partial x^{2}}+2 N_{x y} \frac{\partial^{2} w}{\partial x \partial y}+N_{y} \frac{\partial^{2} w}{\partial y^{2}} \\
&-\mathrm{D}\left(\frac{\partial^{4} \mathrm{w}}{\partial \mathrm{x}^{4}}+2 \frac{\partial^{4} \mathrm{w}}{\partial \mathrm{x}^{2} \partial \mathrm{y}^{2}}+\frac{\partial^{4} \mathrm{w}}{\partial \mathrm{y}^{4}}\right)=0
\end{aligned}
$$

For a plate, loaded only in one direction, $\mathrm{b}$ along $\mathrm{x}$-direction: $N_{x y}=N_{y}=0 \quad$ and $N_{x} \neq 0$

$$
\mathrm{D}\left(\frac{\partial^{4} \mathrm{w}}{\partial \mathrm{x}^{4}}+2 \frac{\partial^{4} \mathrm{w}}{\partial \mathrm{x}^{2} \partial \mathrm{y}^{2}}+\frac{\partial^{4} \mathrm{w}}{\partial \mathrm{y}^{4}}\right)-N_{x} \frac{\partial^{2} w}{\partial x^{2}}=0
$$

Equation 19.0 is the Governing differential Equation of buckled plate loaded along the edge perpendicular to $\mathrm{x}-$ direction.

Although, the mathematical theory behind the Galerkin method is quite complicated, its physical interpretation is relatively simple. The mathematical expression of the method is obtained as follows:

Let a differential equation of a given 2D boundary value problem be of the form:-

$\mathrm{L}[\mathrm{w}(\mathrm{x}, \mathrm{y})]=\mathrm{N}(\mathrm{x}, \mathrm{y})$ in some $2 \mathrm{D}$ domain $\Omega \quad 20.0$

Where,

$\mathrm{w}=\mathrm{w}(\mathrm{x}, \mathrm{y})$ is an unknown function of two variables

$\mathrm{N}=$ a given load term defined also in the domain $\Omega$

$\mathrm{L}=\mathrm{a}$ symbol indicating either a linear or non - linear differential operator.

For instance, for plate bending problems,

$\mathrm{L}[\mathrm{w}(\mathrm{x}, \mathrm{y})] \equiv \mathrm{D} \nabla^{2} \nabla^{2}(\mathrm{~W}(\mathrm{x}, \mathrm{y}))$

$$
\equiv \mathrm{D}\left[\frac{\partial^{4} \mathrm{~W}(\mathrm{x}, \mathrm{y})}{\partial \mathrm{x}^{4}}+2 \frac{\partial^{4} \mathrm{~W}(\mathrm{x}, \mathrm{y})}{\partial \mathrm{x}^{2} \partial \mathrm{y}^{2}}+\frac{\partial^{4} \mathrm{~W}(\mathrm{x}, \mathrm{y})}{\partial \mathrm{y}^{4}}\right]
$$

The function w, must satisfy the prescribed boundary conditions on the boundary $\Gamma$ of that domain.

Typically, one then applies some constraints on the functions space to characterize the space with a finite set of basic functions. An approximate solution of Equation 20.0 is sought in the following form.

$$
w_{N}(x, y)=\sum_{i=1}^{N} \alpha_{i} f_{i}(x, y)
$$


Where,

$\boldsymbol{\alpha}_{\mathbf{i}}$ are unknown coefficients to be determined.

$\mathbf{f}_{\mathbf{i}}(\mathbf{x}, \mathbf{y})$ are the linearly independent functions (they are also called trial or shape functions) that satisfy all the prescribed boundary conditions but not necessarily satisfy Equation 20.0 From Calculus, any two functions $\mathbf{f}_{\mathbf{1}}(\mathbf{x}), \mathbf{f}_{\mathbf{2}}(\mathbf{x})$ are called mutually orthogonal in the interval $(a, b)$ if they satisfy the condition:

$$
\int_{a}^{b} f_{1}(x) f_{2}(x) d x=0
$$

Thus, if a function $\mathbf{w}(\mathbf{x}, \mathbf{y})$ is an exact solution of the given boundary value problem, then, the function $[\mathbf{L}(\mathbf{w})-\mathbf{N}]$ will be orthogonal to any set of functions. Since the deflection function, $\mathbf{w}_{\mathbf{N}}(\mathbf{x}, \mathbf{y})$ in the form of Equation 22.0 is an approximate solution only if Equation 20.0, $[\mathbf{L}(\mathbf{w})-\mathbf{N}] \neq \mathbf{0}$, and it is no longer orthogonal to any set of functions. However, requiring that the magnitude of the function $[\mathbf{L}(\mathbf{w})-\mathbf{N}]$ be minimum. This requirement is equivalent to the condition that the above function should be orthogonal to some bounded set of functions: first of all, to the trial functions $\mathbf{f}_{\mathbf{i}}(\mathbf{x})$. It leads to the following Galerkin equation:

$$
\iint_{\mathbf{A}}\left[L\left(\mathbf{w}_{\mathbf{N}}\right)-\mathbf{N}\right] \mathbf{f}_{\mathbf{i}}(\mathbf{x}, \mathbf{y}) \mathbf{d x d y}=\mathbf{0}
$$

Substituting for Equation 21.0

$$
\begin{array}{r}
\iint_{A}\left[D\left[\frac{\partial^{4} W(x, y)}{\partial x^{4}}+2 \frac{\partial^{4} W(x, y)}{\partial x^{2} \partial y^{2}}+\frac{\partial^{4} W(x, y)}{\partial y^{4}}\right]\right. \\
-N] f_{i}(x, y) d x d y=0 \\
25.0
\end{array}
$$

$$
\begin{aligned}
& \iint_{A}\left[D\left(\frac{\partial^{4} w}{\partial x^{4}}+2 \frac{\partial^{4} w}{\partial x^{2} \partial y^{2}}+\frac{\partial^{4} w}{\partial y^{4}}\right)\right. \\
& \left.-N_{x} \frac{\partial^{2} w}{\partial x^{2}}\right] f_{i}(x, y) d x d y=0 \\
& \iint_{A}\left[D\left(\frac{\partial^{4} w}{\partial x^{4}}+2 \frac{\partial^{4} w}{\partial x^{2} \partial y^{2}}+\frac{\partial^{4} w}{\partial y^{4}}\right)\right. \\
& \left.-N_{x} \frac{\partial}{\partial x}\left(\frac{\partial w}{\partial x}\right)\right] f_{i}(x, y) d x d y=0 \\
& =\frac{\iint_{A} D\left(\frac{\partial^{4} w}{\partial x^{4}}+2 \frac{\partial^{4} w}{\partial x^{2} \partial y^{2}}+\frac{\partial^{4} w}{\partial y^{4}}\right) f_{i}(x, y) d x d y}{\iint_{A} \frac{\partial}{\partial x}\left(\frac{\partial w}{\partial x}\right) f_{i}(x, y) d x d y}
\end{aligned}
$$

In non - dimensional form,

Where:

$$
\mathrm{x}=\mathrm{aR}, \quad \mathrm{y}=\mathrm{bQ} \quad \text { and } P=\frac{a}{b}
$$

$N_{x}$

$$
=\frac{\iint_{\mathrm{A}} \frac{\mathrm{D}}{\mathbf{b}^{2}}\left(\frac{\partial^{4} \mathbf{W}}{\mathbf{P}^{3} \partial \mathbf{R}^{4}}+2 \frac{\partial^{4} \mathbf{W}}{\mathbf{P}^{2} \mathbf{R}^{2} \partial Q^{2}}+\mathbf{P} \frac{\partial^{4} \mathbf{W}}{\partial Q^{4}}\right) \bar{W}(\mathbf{R}, \mathbf{Q}) \mathbf{d R d Q}}{\iint_{\mathrm{A}} \frac{\partial}{P \partial R}\left(\frac{\partial w}{\partial R}\right) \bar{W}(R, Q) \mathbf{R d Q}}
$$

Where, $\mathbf{f}_{\mathbf{i}}(\mathbf{R}, \mathbf{Q})=\overline{\mathbf{W}}$

Figure 1.0 shows a thin rectangular plate subjected to in plane loading $\mathrm{N}_{\mathrm{x}}$ in $\mathrm{x}$ - direction. The plate is all edges clamped.

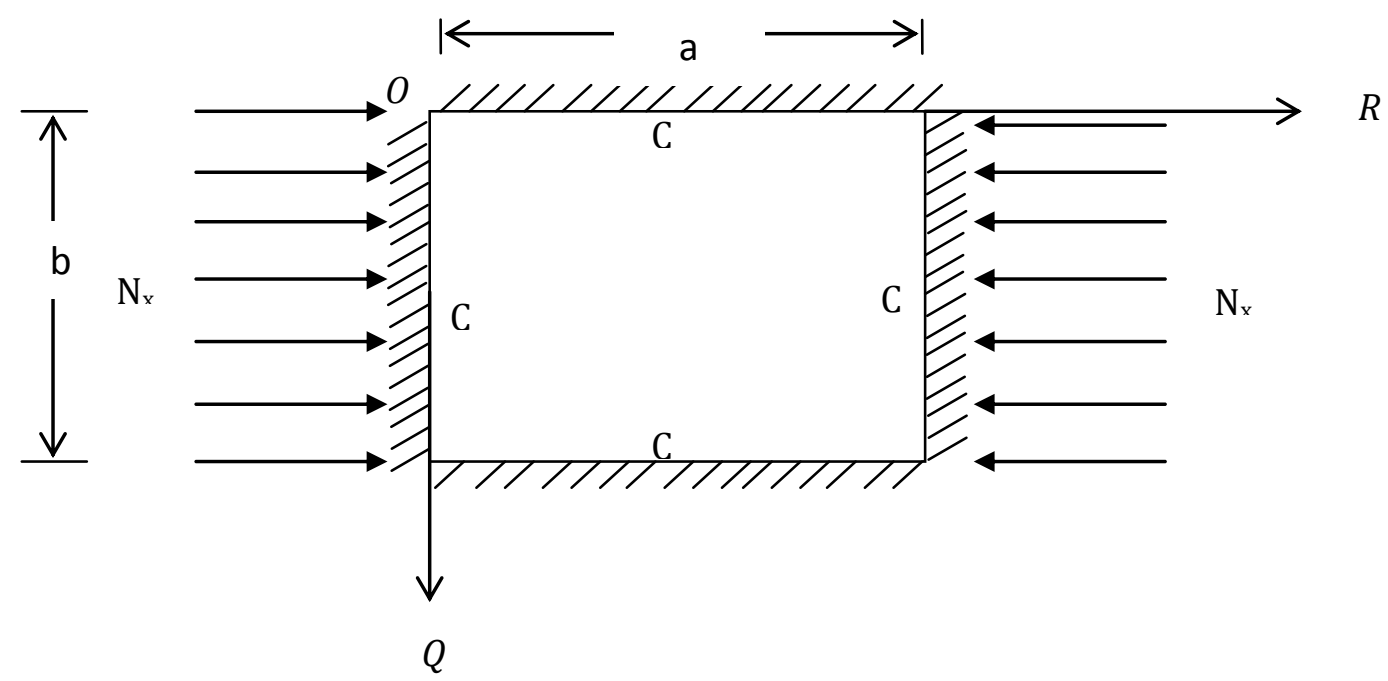

Fig 1: All Edges Clamped plate (CCCC) 
From Equation 16.0, the shape function for $\mathrm{CCCC}$ is given as:

$$
\begin{gathered}
W=A\left(R^{2}-2 R^{3}+R^{4}\right)\left(Q^{2}-2 Q^{3}+Q^{4}\right) \\
\bar{W}=\left(R^{2}-2 R^{3}+R^{4}\right)\left(Q^{2}-2 Q^{3}+Q^{4}\right)
\end{gathered}
$$

Then,

$$
\begin{aligned}
& \frac{D}{b^{2}} \int_{0}^{1} \int_{0}^{1} \frac{\partial^{4} \mathrm{~W}}{\mathrm{P}^{3} \partial R^{4}} \cdot \bar{W} d R d Q=\frac{0.00127 A D}{b^{2} \mathrm{P}^{3}} \\
& \frac{D}{b^{2}} \int_{0}^{1} \int_{0}^{1} P \frac{\partial^{4} \mathrm{~W}}{\partial Q^{4}} \cdot \bar{W} d R d Q=\frac{0.00127 D}{b^{2}} P \\
& \frac{D}{b^{2}} \int_{0}^{1} \int_{0}^{1} \frac{2 \partial^{4} W}{P d R^{2} d Q^{2}} \cdot \bar{W} d R d Q=\frac{0.0007256 D A}{b^{2} \mathrm{P}} \\
& \frac{1}{\mathrm{P}} \iint_{0,0}^{1,1} \frac{\partial \mathrm{W}}{\partial \mathrm{R}} \frac{\partial \overline{\mathrm{W}}}{\partial \mathrm{R}} \mathrm{d} R \mathrm{~d} Q=\frac{0.00003 \mathrm{~A}}{\mathrm{P}} \quad 34.0 \\
& N_{X}=\frac{\frac{0.00127 A D}{b^{2} \mathrm{P}^{3}}+\frac{0.0007256 D A}{b^{2} \mathrm{P}}+\frac{0.00127 A D}{b^{2}} P}{\frac{0.00003 \mathrm{~A}}{\mathrm{P}}} \\
& \begin{array}{l}
N_{X} \\
=\left(\frac{\left(0.00127+0.0007256 P^{2}+0.00127 P^{4}\right) D}{0.00003 P^{2} b^{2}}\right)
\end{array}
\end{aligned}
$$

Introducing $\pi^{2}$ into Equation 3.197 by multiplying both sides $\pi^{2}$ :

$$
\begin{array}{r}
N_{X}=\frac{D \pi^{2}}{b^{2}}\left(\frac{4.2858}{\mathrm{P}^{2}}+2.4487\right. \\
\left.+4.2858 \mathrm{P}^{2}\right)
\end{array}
$$

36. 0

\section{RESULTS AND DISCUSSIONS}

The comparison of the data from this present study, Iyengar (1988) and Ibearugbulem (2012) solution was presented in Table 4.2. In this solution, Iyengar assumed trigonometric series in formulating the shape function. $\mathrm{He}$ got the solution of plate at first buckling mode as:

$$
N_{x}=\left(\frac{4}{P^{2}}+4 P^{2}+2.667\right) \frac{D \pi^{2}}{b^{2}}
$$

Ibearugbulem \& Ezeh (2013) applied Taylor's - MacLaurin's series in formulating the shape function. This they applied to Ritz direct variational method to obtain the solution of plate at first buckling mode as:

$$
N_{x}=\left(\frac{4.255}{P^{2}}+4.255 P^{2}+2.428\right) \frac{D \pi^{2}}{b^{2}}
$$

38.0

" $D$ " means the modulus of rigidity of the plate and " $b$ " means the edge of the plate that received the load.

Where, $\mathrm{K}$ is coefficient of $\frac{D \pi^{2}}{b^{2}}$.

Table 1: K Values for different aspect ratios for CCCC Thin plate Buckling

\begin{tabular}{|l|l|l|l|l|l|}
\hline $\begin{array}{l}\text { ASPECT } \\
\text { RATIO } \\
\text { P=A/B }\end{array}$ & $\begin{array}{l}\text { K VALUM } \\
\text { FYENGAR } \\
(1998)\end{array}$ & $\begin{array}{l}\text { K } \\
\text { FROM VALUES } \\
\text { IBEARUGBULEM } \\
\text { \& EZEH (2013) }\end{array}$ & $\begin{array}{l}\text { K VALUES } \\
\text { FROM } \\
\text { PRESENT } \\
\text { STUDY }\end{array}$ & $\begin{array}{l}\text { PERCENTAGE } \\
\text { DIFFERENCE BETWEEN } \\
\text { PRESENT STUDY AND } \\
\text { INYENGAR (1998) }\end{array}$ & $\begin{array}{l}\text { PERCENTAGE DIFFERENCE } \\
\text { BETWEEN PRESENT STUDY } \\
\text { AND IBEARUGBULEM \& } \\
\text { EZEH (2013) }\end{array}$ \\
\hline 0.1 & 402.707 & 427.971 & 431.072 & 6.580 & 0.719 \\
\hline 0.2 & 102.827 & 108.973 & 109.765 & 6.321 & 0.721 \\
\hline 0.3 & 47.471 & 50.089 & 50.454 & 5.912 & 0.725 \\
\hline 0.4 & 28.307 & 29.703 & 29.921 & 5.393 & 0.729 \\
\hline 0.5 & 19.667 & 20.512 & 20.663 & 4.822 & 0.734 \\
\hline 0.6 & 15.218 & 15.779 & 15.897 & 4.268 & 0.738 \\
\hline 0.7 & 12.790 & 13.197 & 13.295 & 3.798 & 0.742 \\
\hline 0.8 & 11.477 & 11.800 & 11.888 & 3.459 & 0.745 \\
\hline 0.9 & 10.845 & 11.128 & 11.211 & 3.265 & 0.746 \\
\hline 1 & 10.667 & 10.938 & 11.020 & 3.206 & 0.747 \\
\hline \multicolumn{7}{|l}{ AVERAGE } \\
\hline
\end{tabular}


The present study gave a solution to CCCC thin plate buckling, which has average percentage difference with the solution from Iyenger as $4.702 \%$. This is an upper bound approximation. It would also be noticed that the closeness of the two solutions improves as the aspect ratio increases from 0.1 to 1 . Comparing with, Ibearugbulem \& Ezeh (2013), the corresponding percentage difference ranges from $0.719 \%$ to $0.747 \%$. This meant that the solution from this present study is very close to the results of Ibearugbulem \& Ezeh (2013) and is upper bound to the later. Hence, the assumed deflection function was close to the exact shape function.

\section{CONCLUSIONS}

i. Characteristics orthogonal polynomials derived shape functions for rectangular plates are satisfactory in approximating the deformed shape of thin rectangular CCCC plate.

ii. Characteristics orthogonal polynomial derived shape functions for rectangular CCCC plate coincides with results obtained by Ibearugbulem \& Ezeh (2013).

iii. An indirect variation principle (based on Galerkin's method) could be used in confidence to satisfactorily analyze real time rectangular thin plates of various boundary conditions under in- plane loadings.

iv. The results obtained herein are very close to the results obtained by previous research works that used different methods of analysis.

\section{RECOMMENDATIONS}

Future studies should use the shape function derived by Characteristic Orthogonal Polynomials herein and Galerkin's method to analyze plate on elastic foundation.

\section{REFERENCES}

[1] Bhat, R. B. (1985a). Natural Frequencies of Rectangular Plates using Characteristic Orthogonal Polynomials in Rayleigh - Ritz Method. Journal of Sound and Vibration, Vol. 102 (4), pp 493 - 499

[2] Brown, R. E., \& Stone, M. A. (1997). On The Use of Polynomial Series with the Rayleigh Ritz Method. Composite Structures, Vol. 39 (3-4), 191-196

[3] Chakraverty, S. (2009). Development Of Characteristic Orthogonal Polynomials (Cops): In Vibration Problems Vibration of Plates. Boca Raton: CRC Press

[4] Chihara, T. S. (1978). An Introduction to Orthogonal Polynomials. London: Gordon and Breach.

[5] Fok, C. D. (1980). Effects of initial imperfections on the elastic post-buckling behaviour of flat plates. Ph.D. Thesis, Monash University.

[6] Freud, G. (1971). Orthogonal Polynomials. Oxford: Pergamon Press.

[7] Ibearugbulem, O. M., \& Ezeh, J. C. (2013). Instability of Axially Compressed CCCC Thin Rectangular Plate
Using Taylor - Mclaurin's Series Shape Function on Ritz Method. Academic Research International , 4 (1), $346-351$

[8] Iyengar, N. G. (1988). Structural Stability of Columns and Plates. New York: Ellis Horwood Limited.

[9] Kirchoff, G. R. (1885). Vorlesungen über mathematische physic, mechanik (2nd

[10] Levy, S. (1942). "Bending of Rectangular Plates with Large Deflections". NACA, Technical Report, No. 737, Washington, D.C.

[11] Onyeyili, I. O. (2012). Lecture Notes on Advanced Theory of Plates and Shells. FUTO: SPGS.

[12] Saint-Venant. (1883). Discussion in theorie de l'elasticite des corps solide. clebsch, P.704.

[13] Szego, G. (1967). Orthogonal Polynomials (3rd Edition ed.). New York: American Mathematical

[14] Wendroff, B. (1961). On Orthogonal Polynomials. American Mathematical Society (12), 554-555. 